\title{
Optimization of the Model of Abdominal Aortic Aneurysm - Experiment in an Animal Model
}

\author{
Jiří Moláček ${ }^{a}$ Vladislav Třeška ${ }^{a} \quad$ Jiří Kobr $^{b} \quad$ Bohuslav Čertík $^{a} \quad$ Tomáš Skalický $^{a}$ \\ Vilém Kuntscher ${ }^{a}$ Věra Kř́źžkovác \\ Departments of a Vascular Surgery and ${ }^{\mathrm{b}}$ Pediatry, University Hospital, and ${ }^{\mathrm{C}}$ Institute of Histology and Embryology, \\ Medical Faculty, Charles University, Pilsen, Czech Republic
}

\section{Key Words}

Animal aneurysm model · Elastase infusion •

Abdominal aortic aneurysm • Inflammatory response

\begin{abstract}
Background: Many studies have been performed in order to model abdominal aortic aneurysm (AAA) in an experimental animal, most commonly in small laboratory animals. In our study, we tried to find the best AAA model in a pig by using various mechanical and enzymatic mechanisms. Methods: Twenty-two pigs were operated on. We combined 3 mechanisms of creating an AAA, using an intraluminal infusion of porcine pancreatic elastase into the abdominal aortic segment, application of plastic cuff below the renal arteries causing turbulent blood flow, and inserting a patch into the longitudinal aortotomy. Results: We found different results in different groups according to the mechanisms used. In group $A$, with a combination of the intraluminal elastase infusion and application of a stenosing cuff, AAA developed in all 7 animals (100\%). In this group, we also found the largest histological changes in the abdominal aorta samples. Conclusion: The use of intraluminal pancreatic elastase infusion, together with increased turbulent flow caused by the ste-
\end{abstract}

\section{KARGER}

Fax +41613061234 E-Mail karger@karger.ch www.karger.com
(C) 2008 S. Karger AG, Basel

$1018-1172 / 09 / 0461-0001 \$ 24.50 / 0$

Accessible online at:

www.karger.com/jvr nosing cuff, seems to be the best model of AAA in pigs. This model is suitable for further research in the etiopathology of AAA. In fact, it is the first successful approach to a large-caliber native aneurysm model.

Copyright $\odot 2008$ S. Karger AG, Basel

\section{Introduction}

Abdominal aortic aneurysm (AAA) is a disease with persistently growing incidence, and at present, occupies the 10th position in the causes of death in men above 55 years of age. Although diagnosis, therapy and post-operative care are constantly improving, mortality remains high [1-3]. One possible way to reduce the mortality of AAA is to find the causes of AAA inception. The etiopathogenesis of AAA is still not sufficiently clear. Modelling AAA in animals represents one route to a better understanding, as well as to a qualitative improvement in diagnosis and therapy. A number of authors have attempted to create an animal model of AAA using various experiments [4-6].

Many researches emanate from the 1994 paper of Anidjar et al. [4] who created AAA with pancreatic elas- 


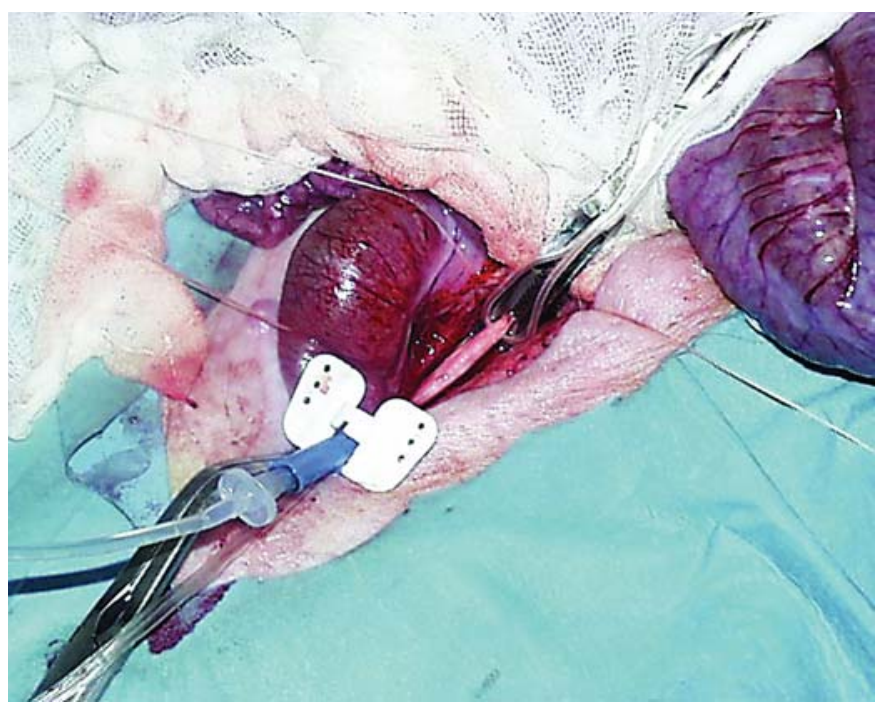

Fig. 1. Infusion of elastase solution into the clamped abdominal aorta.

tase intraluminal infusion in rats. Other authors also mainly worked with mice or rats. We started with Anidjar's model but decided to use other mechanisms for the modelling of AAA, using pigs whose cardiovascular system is very similar to that of the human organism. The aim of our research was to find the best ('optimal') animal AAA model, suitable for further research in the etiopathogenesis, diagnosis and therapy of AAA.

The entire experiment was performed at the experimental centre of the Medical Faculty at Charles University in Pilsen after the approval of the ethical committee for working with experimental animals.

\section{Materials and Methods}

We chose 22 pigs of an average weight of $20 \mathrm{~kg}$, all female, 3 months old. In order to study the mechanism of AAA inception, we used the following methods:

(A) intraluminal infusion of porcine pancreatic elastase into the abdominal aorta + creating turbulent flow in the aorta with a subrenally placed stenosing cuff;

(B) intraluminal infusion of saline + creating turbulent flow in the aorta with a subrenally placed stenosing cuff;

(C) inserting a patch into the longitudinal aortotomy + creating turbulent flow in the aorta with a stenosing cuff;

(D) control group.

Group A ( $\mathrm{n}=7)$ included animals where a combination of intraluminal infusion of porcine pancreatic elastase and subrenal application of a stenosing cuff were used to create AAA. The following procedure was done: under general anaesthesia (azaperone $4 \mathrm{mg} / \mathrm{kg}$, thiopental $5 \mathrm{mg} / \mathrm{kg}$, ketamine $1 \mathrm{mg} / \mathrm{kg}$, fentanyl 0.04

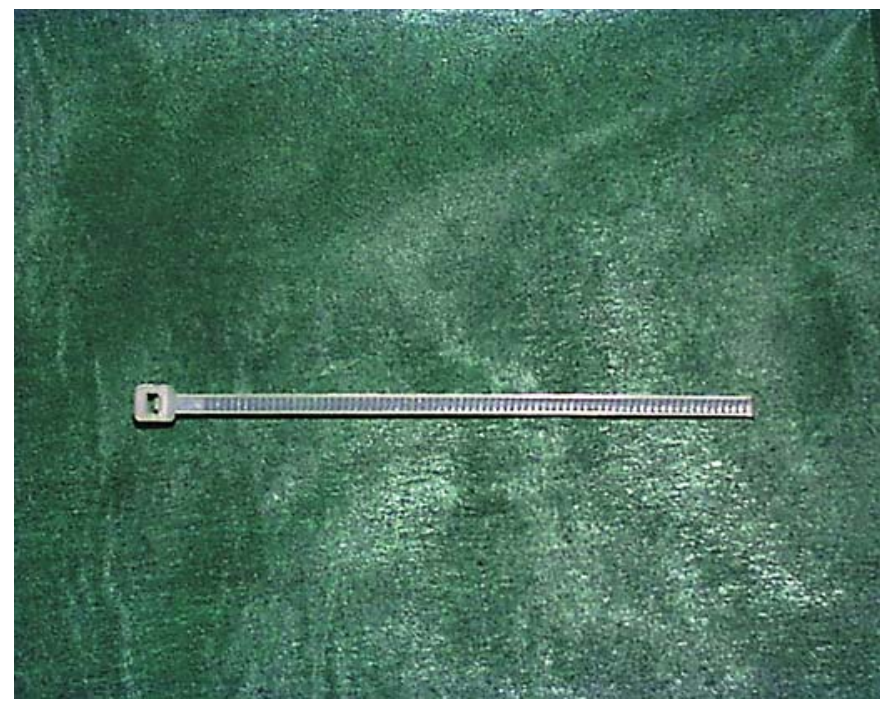

Fig. 2. Cuff for stenosing of subrenal aorta.

$\mathrm{mg} / \mathrm{kg}$ ), we first performed an ultrasound of the abdominal aorta and measured its front-back diameter, then we performed a medial laparotomy, exposed the abdominal aorta which we clamped proximally with a vascular clamp (below the renal arteries) and distally (above the bifurcation), and additionally clamped the accessible lumbar arteries. We inserted a 24 -gauge peripheral intravenous catheter into the abdominal aorta lumen, aspirated the blood and gradually infused the solution of swine pancreatic elastase (Sigma Aldrich, E1250, concentration $14.3 \mathrm{mg} / \mathrm{ml}, 6 \mathrm{IU} / \mathrm{mg}$, volume $5 \mathrm{ml}$ ) (fig. 1). We allowed the solution to act on the aortic wall for $30 \mathrm{~min}$, then we aspirated it from the aorta lumen and released the aorta closure from the vascular clamps. We slightly narrowed the proximal part of the abdominal aorta (below the renal arteries) through the application of a plastic cuff (fig. 2). A palpable thrill in the abdominal aorta demonstrated a pronounced turbulent flow in this area after application of the stenosing cuff. We closed the laparotomy and extubated the animal after awakening from the anaesthesia.

In group B $(n=5)$, we proceeded in a similar way; however, instead of the solution of elastase, we infused a physiological solution. The cuff was placed identically.

In group $C(n=5)$, we again used general anaesthesia, the same approach to the aorta, and after clamping the aorta, we performed a longitudinal aortotomy on its front wall and sewed it up with a 5-mm-wide patch of Dacron (Boston Scientific), after which we again applied a stenosing cuff in the same place (fig. 3). Thus, in this group, we used the mechanism of turbulent flow with a stenosing cuff, together with a sewing patch.

The swine in group $\mathrm{D}(\mathrm{n}=5)$ were not operated on; they were used as a control group.

We monitored all animals for 21 days (this period was fixed at the beginning of the experiment), and during this time period, animals were given normal food and were housed in the cages in the experimental department. In regular intervals of 7 days, we performed abdominal aorta ultrasound and measured its widest 


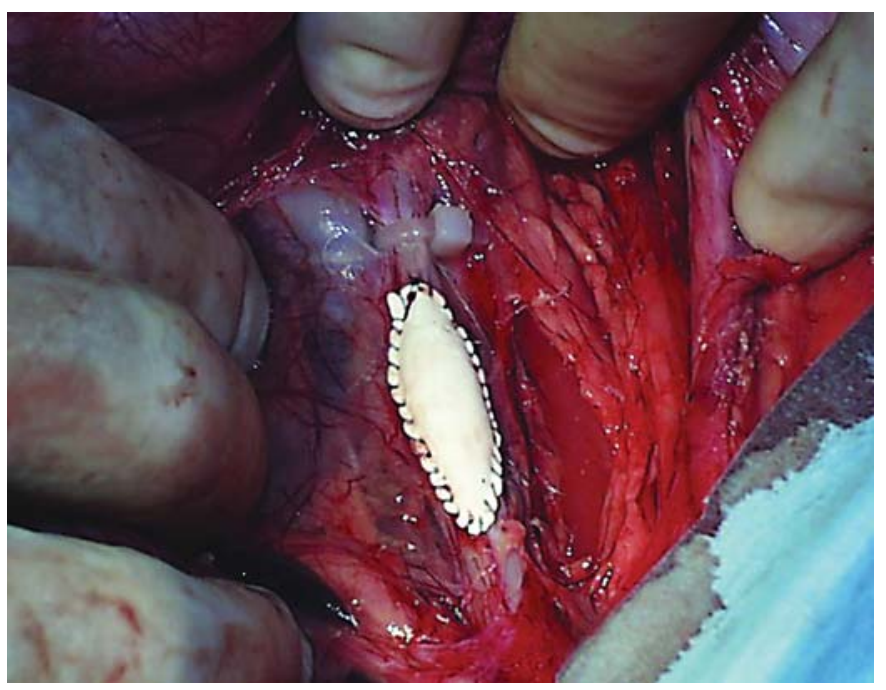

Fig. 3. State after sewing the patch and placing the cuff.

front-back diameter in analgosedation (stresnil $4 \mathrm{mg} / \mathrm{kg}$ i.m.). We expressed the AAA diameter in millimeters and assessed the average value \pm standard deviation (SD). The statistical evaluation was performed by means of the sign test, and $\mathrm{p}<0.05$ was considered statistically significant. On the 21 st day after surgery, i.e. after the third ultrasound control, we again performed a laparotomy, under the same conditions. We resected the whole segment of the abdominal aorta and killed the animal in accordance with the conditions prescribed for working with laboratory animals.

The aorta samples were fixed in $10 \%$ formol and examined histologically.

The aortic wall was evaluated under an optical microscope by experienced histopathologists, specializing in diseases of the vascular system.

Investigators for ultrasound and histologic evaluations were blinded as to the allocation of the pigs to groups A-C or D.

\section{Results}

Already during ultrasound controls, we observed the largest increase in aorta diameter in group A (fig. 4), where we used an intraluminal infusion of elastase solution and a stenosing cuff. In the final stage of the experiment, on the 21st post-operative day, we confirmed the results of sonography during relaparotomy and indeed found typical sacciform aneurysms (fig. 5) in all 7 cases; the front-back diameter was on average 2.14 times larger than the aorta diameter at the beginning of the experiment.

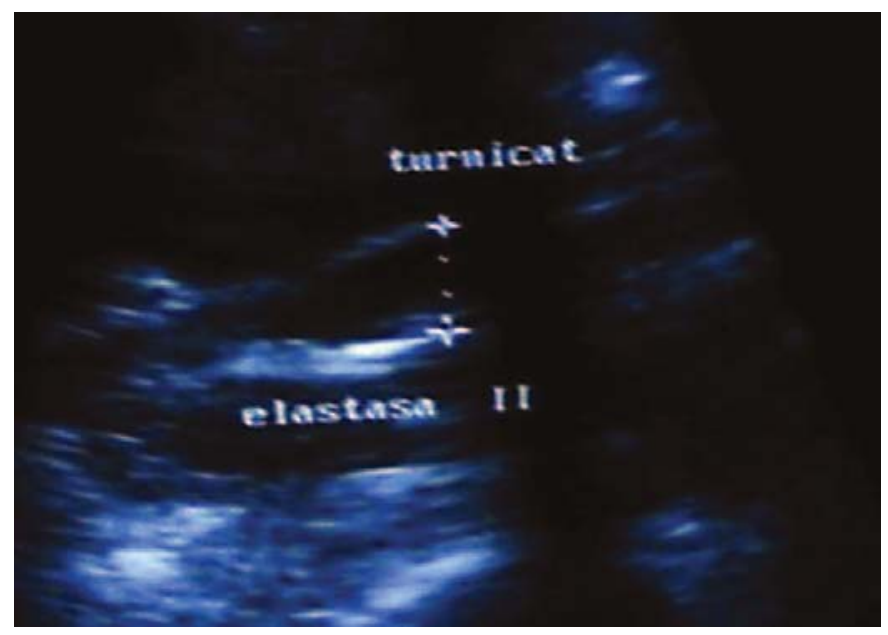

Fig. 4. Sonography of an animal aorta from group A on the 14th post-operative day.

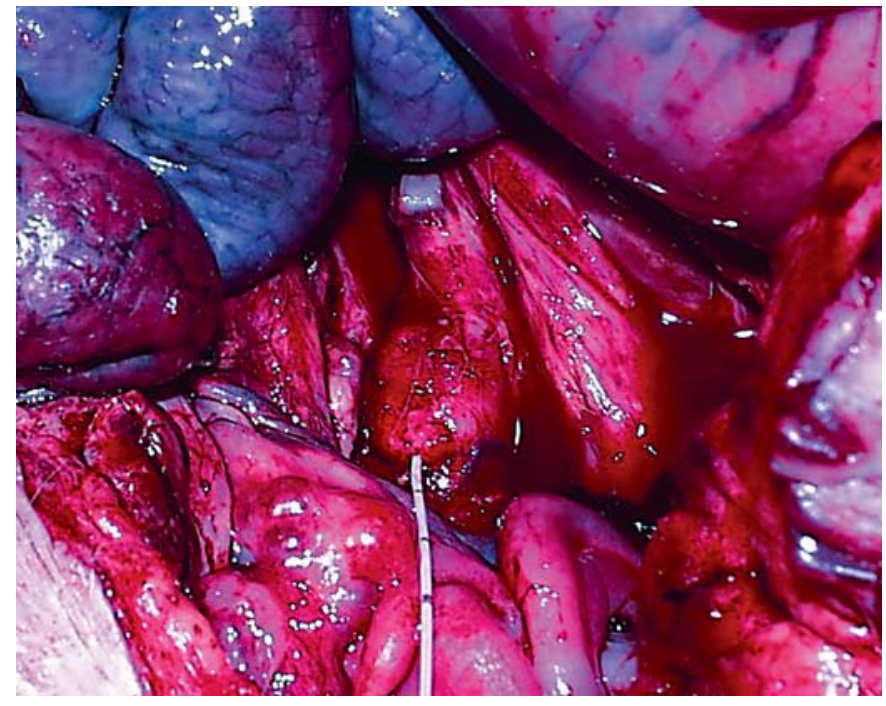

Fig. 5. AAA in an animal from group A during relaparotomy (21st post-operative day).

In group $\mathrm{B}$, there was mild dilation of the aorta (when compared with the control group D), but a typical aneurysm did not develop.

Similarly, in group C, the already 'preformed small AAA' grew more than a normal artery.

In group $\mathrm{D}$, the diameter of the abdominal aorta increased in parallel with the growth of the animal (the daily increase in weight in swine was approximately $0.75-$ $1 \mathrm{~kg}$ ) (table 1). 
Table 1. Average values of aorta sizes at the beginning and the end of the experiment

\begin{tabular}{lllll}
\hline Group & $\begin{array}{l}\text { Average values of aorta size } \\
\text { at the beginning } \pm \mathrm{SD}, \mathrm{mm}\end{array}$ & $\begin{array}{l}\text { Average values of aorta size } \\
\text { at the end } \pm \mathrm{SD}, \mathrm{mm}\end{array}$ & $\begin{array}{l}\text { Average relative } \\
\text { growth } \pm \mathrm{SD}, \mathrm{mm}\end{array}$ & $\begin{array}{l}\text { Average absolute } \\
\text { growth } \pm \text { SD, mm }\end{array}$ \\
\hline A & $7.29 \pm 0.76$ & $15.60 \pm 1.21$ & $2.14 \pm 0.10$ & $8.30 \pm 0.58$ \\
B & $7.10 \pm 0.89$ & $11.80 \pm 1.82$ & $1.67 \pm 0.19$ & $4.70 \pm 1.35$ \\
C & $8.60 \pm 1.14^{*}$ & $14.40 \pm 0.86$ & $1.66 \pm 0.22$ & $5.62 \pm 1.25$ \\
D & $7.20 \pm 0.57$ & $9.20 \pm 0.84$ & $1.28 \pm 0.04$ & $2.00 \pm 0.35$ \\
\hline
\end{tabular}

The biggest average increase in aorta diameter was found in group $\mathrm{A}(8.3 \pm 0.58 \mathrm{~mm})$, compared with groups B ( $4.7 \pm 1.35 \mathrm{~mm}), \mathrm{C}(5.62 \pm 1.25)$ and D $(2.0 \pm 0.35)$.

We statistically analysed values of aortic diameter at the beginning and at the end of the experiment in all animals and compared groups A, B and C with group D. A statistically significant increase was only observed in group $\mathrm{A}$ (compared with group $\mathrm{D} ; \mathrm{p}<0.0156)$. In groups $\mathrm{B}$ and $\mathrm{C}$, we did not find a statistically significant increase (compared with group $\mathrm{D} ; \mathrm{p}<0.0625$ ).

* Diameter of aorta after sewing the patch.

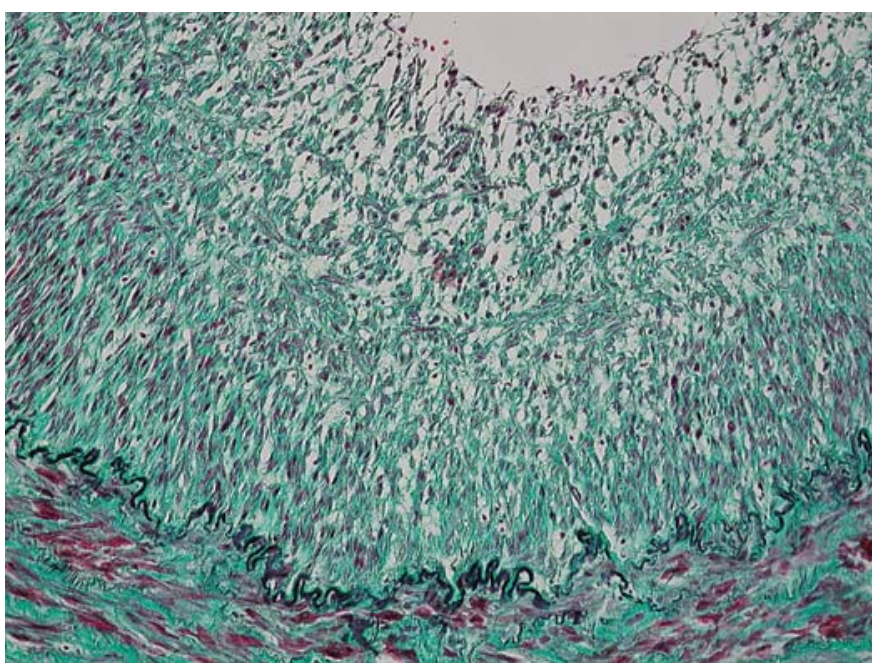

Fig. 6. Histological finding in the aorta of an animal from group A (modified trichromium): thickening of the tunica intima, damaged and fragmented lamina elastica interna, and damaged elastic membranes in the whole of the tunica media, multiplied cells of mesenchymal origin (fibroblasts, smooth muscle cells), inflammatory infiltration in the tunica media and tunica adventitia.

\section{Results of Histological Analysis}

As expected, we detected the greatest changes in the structure of the aortal wall in group A, mainly in the middle part (fig. 6). Smaller changes occurred in the proximal and distal parts of the AAA in this group, as well as in groups B and C. Group D demonstrated completely normal walls of a healthy aorta.
Characteristic changes in group A were as follows: thickening of the tunica intima, damaged and fragmented lamina elastica interna, and damaged elastic membranes in the whole of the tunica media. There was a very interesting finding of multiplied cells of mesenchymal origin (fibroblasts, smooth muscle cells) and their proliferation. There was also a pronounced inflammatory infiltration in the tunica media and tunica adventitia. Inflammatory changes even affected the vasa vasorum, which were completely obliterated in places.

\section{Discussion}

AAA etiopathogenesis is almost certainly a multifactorial process in which both biochemical (degradation of elastin and collagen) and mechanical influences dominate (turbulent blood flow, hypertension). Animal experiments represent one way to understand the process of AAA inception $[5,6]$.

Our experiment related to the results of previous experimental studies and tried to find the best animal model of AAA which might be used for further research in this area.

We verified that the effect of elastase on the tunica intima and lamina elastica interna triggers the whole mechanism, at the beginning of which is the entry of inflammatory cells (monocytes, macrophages, lymphocytes) into the aortal wall. Elastase activity itself, but very probably mostly the activity of the above-mentioned cells, leads to further degradation of elastin $[7,8]$. The degradation products of elastin then stimulate the release of pro- 
teolytic enzymes - metalloproteinases 1, 2, 3 and 9 whose activity leads to the degradation of the intercellular matrix and its structural components (collagen, elastin, laminin, fibronectin and proteoglycan) [9-12].

Turbulent flow occurs under normal circumstances even in a healthy aorta, above its bifurcation in the pelvic artery. Some studies, dealing with mechanical influences on the abdominal aortal wall regarding AAA development, confirmed such a relation [13]. In spite of that, on the basis of our experiment, we believe that turbulent flow does not have an essential influence at the beginning of AAA. It is rather that the processes leading to the damage of the 'protective' barrier (tunica intima, lamina elastica interna) of the aortal wall play an undoubted role, and thus, it subsequently triggers a whole cascade of processes destroying the intercellular matrix [14]. Thus, turbulent flow in the aorta lumen certainly has an essential effect on the increase of AAA, because the damaged wall cannot resist the mechanical pressure of the blood flow.

On the basis of our results, we believe that creating an experimental AAA model through the effect of elastase on the aortic wall in combination with turbulent blood flow in the aorta is a model which can be well used not only for further research into etiopathogenetic processes leading to the development of an aneurysm, but also for the study of new diagnostic and therapeutic possibilities. In fact, it is the first successful approach to a large-caliber native aneurysm model. If the new experience acquired through these models contributes to the construction of more superior stent grafts or finds a location in the pathogenesis of an aneurysm where we could intervene therapeutically, then these experiments are not only significant, but will enable us to save the lives of more patients with this very serious disease.

\section{Acknowledgments}

This study was supported by the research project MSM, grant no. 0021620819 from the Czech Republic.

\section{References}

1 Keller JA, Weinberg A, Arons R, et al: Two decades of abdominal aortic aneurysm repair: have we made any progress? J Vasc Surg 2000;32:1091-1100.

-2 Johnston KW: Multicentre prospective study of nonruptured abdominal aortic aneurysma. J Vasc Surg 1989;9:437-441.

-3 Chuter RAM, Senft G, Hopkinson BR: European experience with a system for bifurcated stent-graft insertion. J Endovasc Surg 1997; 4:13-22.

-4 Anidjar S, Dobrin PB, Chejfec G, Michel JB: Experimental study of determinants of aneurysmal expansion of the abdominal aorta. Ann Vasc Surg 1994;8:127-136.

5 Marinov GR, Marois Y, Paris E, Roby P, Formichi M, Douville Y: Can the infusion of elastase in the abdominal aorta of the Yucatan miniature swine consistently produce experimental aneurysms. J Invest Surg 1997; 10:129-150
6 Carsten CG 3rd, Calton WC, Johanning JM, Armstrong PG, Franklin DP, Carey DJ, Elmore JR: Elastase is not sufficient to induce experimental abdominal aneurysms. J Vasc Surg 2001;33:1255-1262.

7 White JV, Ghaas K, Phillips SJ, Comerota AJ: Adventitial elastolysis is a primary event in aneurysms formation. J Vasc Surg 1993;17: 371-381.

8 White JV: Aneurysm formation in vivo by the degradation of adventitial elastin. J Vasc Surg 1994;20:153-155.

9 Szekanecz Z, Sha M, Pearce W, Koch AE: Intercellular adhesion molecule 1 (ICAM-1) expression and soluble ICAM-1 (sICAM-1) production by cytokine-activated human aortic endothelial cells: a possible role of ICAM-1 and sICAM-1 in atherosclerotic abdominal aortic aneurysm. Clin Exp Immunol 1994;98:337-343.
10 Blann AD, Devine C, Amiral J, McCollum $\mathrm{CN}$ : Soluble adhesion molecules, endothelial markers and atherosclerosis risk factors in abdominal aortic aneurysms: a comparison with claudicants and healthy controls. Blood Coagul Fibrinolysis 1989;9:479-484.

11 Davic CA, Pearce W, Haines GK: Increased ICAM-1 expression in aortic disease. J Vasc Surg 1993; 18:875-880.

12 Vine N, Powel JT: Metalloproteinases in degenerative aortic disease. Clin Sci 1991;81: 233-239.

13 MacSweeny STR, Powel JT, Greenhalgh RM: Pathogenesis of abdominal aortic aneurysm. Brit J Surg 1994;81:935-941.

14 Tonar Z, Němeček S, Kočová J, Třeška J, Moláček J, Kohoutek T, Hadravská Š: Microscopic image analysis of elastin network in samples of normal, atherosclerotic and aneurysmatic abdominal aorta and its biomechanical implications. J Appl Biomed 2003; 1 : 149-160. 